\title{
The Role of Resource Consumption Accounting (RCA) in Improving Cost Management in the Jordanian Commercial Banks
}

\author{
Abdulkhaliq M. Al-Rawi ${ }^{1}$ \& Hiba Abd al-Hafiz ${ }^{2}$ \\ 1 ISRA University, Jordan \\ 2 Income and Sales Tax Department - Karak, Jordan \\ Correspondence: Abdulkhaliq M. Al-Rawi, ISRA University, P.O. Box (22) \& (33) - Area Code Amman 11622 \\ Jordan. Tel: 962-777-252-681. E-mail: alrawi48@ hotmail.com
}

Received: August 4, 2018

Accepted: September 4, 2018

Online Published: September 15, 2018

doi:10.5539/ijef.v10n10p28

URL: https://doi.org/10.5539/ijef.v10n10p28

\begin{abstract}
This research aims to demonstrate the ability of the resource consumption accounting system to create an addition to cost management at the Jordanian commercial banks through the following dimensions: providing appropriate information, reducing costs, and improving the quality of the cost accounting outputs of Jordanian commercial banks. The researchers relied on several study methods, represented in descriptive methodology for the purpose of scientific organized analysis and interpretation, the use of the questionnaire adopted on the basis of the theoretical literature of the previous studies and the analytical approach to describe the phenomenon as it is in fact and then to analyze, interpret and link it with other phenomena, in addition to the statistical approach by using statistical methods in processing and analyzing data pertinent to the subject matter of this research. The conclusions of the research have shown that resource consumption accounting system plays a positive role in cost management by providing appropriate information, reducing costs and improving the quality of banking services in Jordanian commercial banks. The most important recommendations were to urge the decision makers in Jordanian commercial banks to use of the resource consumption accounting system because of its positive impact on cost management, and the raise of awareness of cost accountants in Jordanian commercial banks of the need to develop the cost systems currently used to meet cost management needs.
\end{abstract}

Keywords: Resource Consumption Accounting (RCA), Cost Management (CM), Resources Management (RM)

\section{Introduction:}

The resource consumption accounting system is one of the tools that helps enterprises succeed by their ability to allocate available resources more efficiently and achieve greater accuracy in allocating costs to activities. Due to the importance of the subject, the researchers found it appropriate to research it to find out how much Applicability in Jordanian commercial bank, And the role it can play to manage the bank in allocating resources more efficiently and achieving the competitive advantage required by the bank in light of the large and growing number of commercial banks in Jordan. We have been preceded by many researchers in Jordan and abroad, but the focus was mainly on industrial enterprises. The majority of them concluded that the (RCA) system leads to higher accuracy in allocating costs and better ability to allocate the resources and energies available in industrial establishments in particular. from these researchers: Azim (2012), Hadi (2012), Dayim (2014), Abbas and Wagdi (2014), Elmaci (2014). Ramgiet et al. (2012) disagreed with the opinion, Where he sees that the (RCA) system complex more than other costs systems such as (TDABC).

Resource consumption accounting (RCA) is a tool or system of modern cost tools or systems. It is characterized by providing comprehensive and adequate information that helps to work on sound resource planning, reduce costs, control and detect the existing idle or surplus energies. It helps to make rigorous strategic and operational decisions, which will increase the competitiveness of the enterprise and provide the best ways to satisfy customers. This tool can provide what traditional systems have been unable to provide if it was properly applied.

Therefore, the two researchers were interested in studying the topic as being reliably new to the Jordanian environment in general and to the commercial banks in particular, which were not studied in the banking sector, according to the researchers' knowledge, In order to know the role that the (RCA) system can play in providing appropriate information that contributes to better allocation of resources and capacities and reducing costs. 


\section{Literature Review}

\subsection{Cost Management}

\subsubsection{Concept of Cost Management}

The concept of cost management is used to describe managers' short- and long-term efforts that cause reduction of product cost and increase revenue. In addition, information derived from the accounting system helps to manage cost, but the information provided and the accounting system itself do not represent cost management. The quality of information derived from the accounting system depends on the cost model used in the enterprise (Kiwan, 2013, p. 112).

Cost management has been defined as "the management that operates from an advanced managerial and behavioral perspective, with the aim of providing a product with the specifications and quality meet the continuous customer's satisfaction, at low cost and real prices, based on technical methods and advanced tools" (Basile, 2007, p. 138). Horngren defined cost management as a description of management practices in lowering cost and control cost continuously to meet the satisfaction of its customers. (Horngren, 2012, p. 4).

Cost management is also defined as the collection of actual cost data, comparing with budget data, and then taking appropriate corrective action. It is the last critical function of project management, including resource planning, cost estimation, cost balancing, cost control, and making changes (Al-Natur, 2013, 281).

In view of the researchers, all the above definitions agree that cost management is the administrative practices and behaviorscarried out by the management to control costs in all respects that ensure the provision of products at lower costs and high quality to satisfy customers and remain viable in competitive markets.

\subsubsection{Objectives of Cost Management}

Cost Management objectives: The primary objective of cost management is to optimize the economic use of available resources, thereby reducing the areas of waste, misuse and directing cost to essential activities that add value to the product. The most important objective is to achieve customer satisfaction by offering the product the quality and specifications required at the lowest possible price (al-Sammani, 2016, p. 42).

There is a set of comprehensive cost management objectives (Al Hussein, 2016, p. 54)

1) Design an effective cost management system to match the organization's internal environment and cost structures.

2) Prioritization of resource consumption.

3) Responding to the necessary profit requirements through the organization of work, employees and exchange behaviors.

4) Development of the organizational strategy through the objectives set.

5) Determining the cost of significant activities, to determine the efficiency and effectiveness of the performance of activities.

6) Identify and evaluate good activities that can improve future performance.

\subsubsection{Cost Management Plan}

It can be said that the cost management plan is the model in which the method or mechanism described by which the enterprise will plan for the requirements, estimate the costs, design the control system and correct the deviations in the enterprise.

The cost management plan includes the following activities: (Hilal, 2012, p. 35):

a) Resource planning: this activity includes the identification of materials required to perform certain project, the necessary quantities of each resource and the identification of the sources to get such resources on time of need.

b) Cost estimate: This activity relates to the preparation of cost estimate required to obtain the resources previously estimated, and perhaps the time of need for these amounts.

c) Cost balancing, Preparation of cost balances; it means the activity related to the allocation of pre-estimated amounts for the cost of resources to the detailed elements of required works to build a basic, easily tracked cost standard, and helps to measure the performance of business cost.

d) Cost Control: it includes the following works:

1) Influencing the factors that cause the changes in the basic criterion of cost. 
2) Determines whether the basic criterion of cost has changed.

3) Managing change in these standards if they actually occurred.

\subsection{Resource Consumption Accounting (RCA)}

\subsubsection{Preface}

The Resource Consumption Accounting system (RCA) was introduced in 2002 as one of the cost-measurement entries that have emerged in the United States and many European countries, as the system (RCA) is a basic management accounting approach that is strictly applied to provide information that can be used to maximize the value The organization. Its philosophy is based on the German cost input and includes the best principles on which the cost input is based on activity. (Ali, 2013, p. 260).

The International Federation of Accountants (IFAC) included in 2009 resource consumption accounts in the manual of good cost management practicing in its report, entitled "Evaluating the Costing Journey: A Costing Levels Continuum Maturity Model”.

(RCA) system has been used by Consortium of Advanced Management - International (CAM-I) as a result of focusing on theoretical resource capacity based on the division of the resources of economic units into three categories: (Abdel Azim, 2012, pp. 110-112).

Productive resources: It refers to the resources that provide or produce a service to achieve the ultimate purpose, which is the production of commodity or providing service.

1) Non-productive resources: refers to resources that are involved in the maintenance, follow-up, creation and use of assistive devices.

2) Unutilized resources: It refers to unutilized resources in the core activity because of low demand, or a surplus as a result of the increased energy available for the current production process than the volume of demand.

The resource consumption accounting system begins at the cost target and then goes to a range of activities that constitute, in the aggregate, the operations of the Economic Unit to study the impact of these activities and to work on the appropriate consumption of available resources. This helps to understand the nature of the relationships between the change in volume of production and change in the cost of resource consumption.

\subsubsection{Concept of Resource Consumption Accounting (RCA)}

Resource consumption accounting is a cost-management system that combines the principles of German cost management (accounting for marginal and planned costs) and an activity-based cost system (based on quantity) and thus uses comprehensive management accounting information systems that allow the merging of both Analysis of resources and activities. (Al Gharouri, 2010, p. 350).

Ali introduced it as an "input that blends the ideas of the activity-based cost input and the German input to provide the management with accurate information on resources allocation based on the perspectives of activities/operations and identifying the idle energies of resources" (Ali, 2013, p. 264).

It has also been defined as a cost-management accounting tool that provides appropriate information on how to efficiently exploit available resources, employ idle energies and strengthen multiple administrative decision-making at the organization (Shahin, 2010, p. 219).

It has also been defined as a cost-effective tool that is comprehensive in its ability to provide appropriate and accurate information on the company's activities and to detect idle energy, thus helping to optimize resource utilization and decision-making. (al-Sammani, 2016, p. 23).

It has been defined as an entry point for management accounting, which is focused on the availability of reliable information to reduce costs, increase revenue, and improve production capacity in the organizations and greater success in achieving the goals in the presence of a high competitive market.

The researchers note, through the above definitions, that they all agree that resource consumption accounting is a tool or entry of modern management accounting and is the result of the merger between the German cost accounting systems and the activity-based cost accounting, and has come to help management make decisions is to optimize the use of resources in a way that reduces costs and increases revenue while maintaining and sustaining competitive markets.

\subsubsection{Objectives of Resource Consumption Accounting}

The main objective of the resource consumption accounting is to optimize available enterprise resources, reduce 
production costs, meet customer desires and support the competitive position of the enterprise. The resource consumption accounting system seeks to achieve a number of objectives including: (see Al-Hussein, 2016, pp. 27-28).

Providing basic information on the organization's resources, Studying the impact of the nature of cost on the resource consumption, Controls the use of resources, Measuring the progress towards the objectives of reducing the utilization costs of both used and unused resources, Highlights the ability of resources to create value added to the client, Providing an integrated framework for resources within the organization from the available angle and the mutual relations between them and how to utilize them efficiently, Linking the cost of product and the actual materials depleted by the organization activities and the energy of each, and to achieve different control concepts.

From the above, the researchers agree with the main objective of resource consumption accounting and believe it aims to use the resources available in the organization and to exploit them in the best way in order to reduce the cost, while keeping product quality, and to meet customer desires as well as to support the competitive position of the enterprise.

\subsubsection{Basic principles of Resource Consumption Accounting}

Resource consumption accounting is based on three basic principles: resources, cost nature and quantity methodology. Resource consumption accounting follows the same methodology as the activity-based cost system, but the focus is on resources. They use concepts such as resource engines, cost pools, and activities. The following is an explanation of the dimensions or principles of Resource Consumption Accounting (al-Gharouri, 2010, p. 253).

\section{1) Holistic view of resources}

This principle is based on the holistic view of resources through the resources allocated to operations and activities within the enterprise, on the basis that the energy examined and studied as a function of resources and that the pools of these resources are only a means of energy management, thus Resource consumption accounting focuses on the overall concept of resources and collects them in resource pools to include costs associated with each resource quality and knowledge of the relationship between each resource. Building of resource pools depends on the key idea, which is that resources must include all costs according to the general logic that is the origin of the costs is due to the fact that it is a resource service. This method focuses not only on the resource relationship with activities but rather on the reciprocal relationship between the resources because some resources exist to serve other resources (Abkar, 2014, p. 170).

The resource cost reflects the nature of the resource itself and; for example, salaries and benefits in kind are considered the cost of human resources, while expenses related to maintenance, depreciation and remuneration of technicians are considered the cost of the machines and, accordingly, the enterprise consists of a particular set of resources to be borne in operation and utilization of a particular set of expenditures that reflect the cost of exploiting resources. The resource consumption accounting model recognizes the existence of unutilized portion of the supplier's energy is the normal conditions, but must not be added to the cost of the products but is carried over to the outcome accounts at the end of the fiscal year (Kiwan, 2013, p. 1125).

Operation costs in the resource consumption accounting system represent only the cost of the resource that flows from the resource pools to the measurement of cost units by resource drivers, taking into account the interrelationship of the resources, so that each resource may benefit another resource and get benefit from another resource. Some resources can be useful to direct costs, thus helping to strengthen the nature of the cost and the emergence of the idle energy places (Khattab, 2019, p. 19).

Resource consumption accounting does not allocate costs to products but follows the use of resources in quantity, i.e. (in resource units) rather than value, where focuses will be on the unavoidable nature of the resource rather than the current focus on cost behavior. The cost is divided into fixed and variable costs, and therefore the management of the enterprise must divide resources into avoidable resources and unavoidable resources, while the traditional approach focused on charging costs and cost behavior in its response to the activity, and the resource consumption accounting is based on focusing resource testing (al-Gharouri, 2010, p. 354).

The resource consumption accounting does not impose an activity-based allocation when it considers that this is inappropriate but allocates the necessary costs, as there are costs that can be properly accounted for, and the focus on resources in this system has specific requirements. Such requirements include the following (Abkar, 2014, p. 171).

a) Energy identification and management as the energy management lies in sources. 
b) Work to make energy, both idle energy and surplus energy, clear through full disclosure, but not charging them to products or other cost targets.

c) Constant use of the concept of available energy (theoretical and practical) for the common size.

\section{2) Nature of Cost}

The resource consumption accounting model classifies the costs of each resource into two groups, namely fixed cost elements and variable cost elements. The classification on this basis is based on the relationship of these elements to the outputs of each resource not at the overall of enterprise (Kiwan, 2013, p. 1128).

The resource consumption accounting system distinguishes between two basic dimensions of the nature of the cost (Kommi, 2007, p. 183).

a) First dimension: The preliminary nature of the cost, whether fixed or variable, according to the resource consumption points. The organizational or strategic choices determine the type of cost when they occur.

b) The second dimension: the potential nature of variable costs that interpret the probability of a proportional change of variable costs at the point of consumption and therefore the method of allocating costs should be linked to resource consumption models so that variable costs are addressed either proportionately or fixed costs, while the initial nature of fixed costs does not change with resource consumption models.

Therefore, the resource consumption accounting system assumes that all resources will be consumed with the associated costs, either consistently or proportionately, hence the fixed costs do not change with the resource consumption models. (Al-Danaf, 2013, p. 97).

\section{3) The use of Cost Model on Quantitative Basis}

The accounting model on resource consumption relies on the measurement of resource outputs in the form of quantity units. These units are represented in direct working hours, number of KW of electricity, the number of turnover hours of machines etc. The planned and actual cost is allocated to different cost units on the basis of quantities consumed as outputs of these resources, taking into account the causal relationships between the depleted actual resources and the unit cost and then the monetary value, not in advance, as in the case of conventional cost systems (example; 5 hours of operation/production unit).If such causal relationships cannot be established, the allocation of costs takes place at the higher organizational level of the enterprise, for example, if sales volume declines, both the enterprise management and the sales management are responsible for such decline, and therefore must bear these costs i.e. (excess energy) and the products cost should not be inflated thereby. Under other cost systems applied on a (volume-activity) basis, the relationships between depleted resources and cost units are expressed in direct cash, which does not give any explanation on the explanatory nature of this statement, thus may result to improper administrative decisions and inaccuracy in the cost allocations, especially in case of the existence of an idle or surplus energy, and then an incorrect inflation will take place at productive unit (Kiwan, 2013, p. 1127).

\subsubsection{Elements of Resource Consumption Accounting}

The components of the resource consumption accounting application are: (Al-Sammani, 2016, p. 32)

\section{1) Coherence of energy measures in each resource pool}

To overcome the problem of heterogeneity of energy measures in each resource pool, this input determines a measure of outputs in each resource pool. This measure is homogenous to energy management, where it provides a view of how resources are used. Regardless of the variety of activities performed by resources, it focusses on the nature of resources relationship, and therefore provides a perspective for the precise choice of the outputs scale.

\section{2) Effectiveness of idle/surplus energy management:}

To determine the efficiency in energy management, the effectiveness of the management of idle energy is summarized in the following points:
a. Energy exists in the resources not in activities.
b. Idle or surplus energy should be reported as deviations.
c. Idle energy should not be allocated in any manner to the service unit.
d. Tracking the idle energy to the person in charge so as can be controlled.

\section{3) Interrelationships between the resource pools}


The quantity of output for each section is determined on the basis of a ratio or a constant rate for each unit of output, such as the number of direct working hours or the number of hours of operation of the machine, so there are proportional relations with the outputs, and also there are constant relationships with the outputs.

The characteristics of these relations are: (Al-Danaf, 2013, p. 92).

a. The interrelationships are a function of the resources used.

b. The interrelationships are reciprocal relations.

c. The interrelationships are based on the quantities of resource outputs.

d. The interrelationship affects the nature of cost nature on time of consumption.

\section{4) The use of cost system based on resources quantity}

It represents the backbone of the resource consumption accounting and it is deemed a support for charging all the cost components through the resource pools to other resource pools or to direct cost measurement subjects.

\section{5) Management of resources and supportive of administrative decisions}

This is done at all administrative levels to manage energy at operational levels, understand the initial and proportionate nature of costs at tactical levels and understand decisions related to marketing services at strategic levels.

2.2.6 Steps of Applying the Resource Consumption Accounting in the Organizations (Al-Natur, 2013, p. 288)

1) Division of all sections (activities) into productive and service sections, then each productive and assistant section will be divided into resource pools or cost centres on an activity basis. The input of each resource pool is determined on a quantitative basis.

2) Classification of activities into productive and unproductive activities.

3) Calculation the costs of overall inputs at their initial quality incurred by each pool and the secondary costs transferred to a pool from other pools.

4) Identification of output cost drives and cost allocation ratio for the other resource pools or final cost placements.

Cost allocation ratio $=$ overall cost of inputs/the input capacity of the resource pool receiving the service

This method of allocation provided a causal relationship

5) Fragmentation of the cost of inputs for each resource pool into fixed and variable elements based on response principle.

6) Determination cost of cost position according to real benefit of the resource.

7) Calculation of unused energy of the resource pools and take remedy action.

\subsection{Previous Studies}

By reviewing a number of previous studies on the (RCA) system, the two researchers noted the concentration of most studies on industrial companies. These studies include: (Al Natur, 2013), which aims to develop a scientific framework to help in the presence of changes in the traditional methods of cost in the Jordanian industrial companies. And the study (Al-Sawafiri \& Al-Nafie, 2013), which aimed at addressing the information gap between the traditional allocation methods and the modern methods and benefiting from the advantages of the the system of costs of time-oriented (TDABC) and (RCA) system in the classification of industrial operations in the Qassim cement Company. The aim of the (Abdul-Dayem, 2014) study is determine the role of the (RCA) system, and value flow path system that will help improve the quality of the cost measurement. And The study of ( Abbas \& Wagdi, 2014), aimed at conducting a competitive analytical study between the (ABC) and (RCA) systems in order to adopt a cost effective system. But it found that the majority of Egyptian industrial companies implement the $(\mathrm{ABC})$ system by $57 \%$ Companies while the (RCA) does not constitute a 5\%, while other companies apply other cost systems. The (Elmaci, 2014) study aimed to propose a model for the use of the (BSC) with (RCA) in the performance management of enterprises in Turkey. Opinion (Ramji et al., 2012), differs from previous researchers that (RCA) is a complex system compared to (TDABC) and other cost systems, making it difficult to apply.

\subsection{What Distinguishes This Research from Previous Studies}

This search for previous studies has the following features: 
- It is the first study (according to the researchers) on the banking sector in Jordan.

- The scarcity of studies related to the Resource Consumption Accounting (RCA), whether in the industrial or service sector, discusses the application of (RCA) in Jordan, to the knowledge of the researchers.

\section{Research Methodology}

\subsection{The Problem}

In the light of the review of the previous studies and the researchers' knowledge of many of the organizational structures of the Jordanian commercial banks, it was noted that there are no independent organizational units to manage the cost that would interest the application of modern cost systems such as the (RCA) system, thus depriving the bank of the necessary information to assist in the allocation Optimizing available of resources and channeling unemployed energies into more productive activities that help the bank reduce costs and achieve competitive advantage.

\section{The Research Problem can be formulated in the two following to questions:}

1) Is there a role for the (RCA) system in providing appropriate information for resource allocation in Jordanian commercial banks?

2) Is there a role for (RCA) system in reducing costs in Jordanian commercial banks?

\subsection{Hypotheses}

The research is based on two main hypotheses:

1) There is no role for (RCA) System in providing appropriate information for resource allocation in Jordanian commercial banks.

2) There is no role for (RCA) System in reducing cost in Jordanian commercial Banks.

\subsection{Research Terms}

\section{Cost Management}

It is the management which operates from advanced intellectual and behavioral perspective with the intention of providing a product with specifications and the quality of continuously satisfy consumers' tastes at low cost and real prices based on advanced techniques and tools (Basile, 2007, p. 138).

\section{Resources}

The assets and capabilities of the enterprise; such as the financial resources, human resources, technical and informational resources, as well as material resources consisting of tangible assets; such as land, factories and equipment, and the moral resources represented in skills and experience of the individuals, the patents and the reputation of the enterprise. These resources work on creating the appropriate conditions for the enterprise (Hijazi, 2012, p. 185).

\section{Resource Consumption Accounting (RCA)}

A cost-management accounting tool to provide appropriate information on how to efficiently utilize available resources and to employ idle/surplus energies by contributing to increase productivity, lowering the cost of the product and thus increasing the organization's profits and supporting its competitive position (Kommi, 2007, p.182).

\subsection{Methodology}

The descriptive approach has been used for the purpose of structured scientific analysis and interpretation and through the use of the questionnaire which has been prepared on the basis of the theoretical literature of the previous studies and metrics developed in accordance with the commercial banking environment for the purpose of collecting the raw data. The analytical approach is used to describe the phenomenon as it is in fact, and then analyzed, interpreted and linked to other phenomena. The statistical approach is used through the use of statistical methods in processing and analyzing data related to the subject of this research.

\subsection{Community and Sample}

The research community consists of all Jordanian commercial banks. The sample of the study consisted of all commercial banks in Kerak governorate, which are nine (9) banks and their branches consisting of (15) branches. A comprehensive survey was conducted on 54 individuals involved in the cost management of the Jordanian commercial banks at the Kerak Governorate, consisting of the Directors of the Bank, the Deputy Directors and the Chiefs of Section. The questionnaire was distributed to all of them, and the collected questionnaires were 
(53). One of the collected questionnaire was found invalid for analysis, thus the number of samples analyzed was (52).

\subsection{Distribution of Search Sample Members}

The research sample is distributed in (Table 1) as follows:

Table 1. Distribution of research sample members

\begin{tabular}{clcc}
\hline The variable & Variable class & Number & Percentage \\
\hline \multirow{3}{*}{ Sex } & Female & 13 & $25.0 \%$ \\
& Male & 39 & $75.0 \%$ \\
& Total & 52 & $100.0 \%$ \\
\hline \multirow{3}{*}{ Career Center } & Director & 15 & $28.8 \%$ \\
& Assistant Director & 16 & $30.8 \%$ \\
& Head of Department & 17 & $32.7 \%$ \\
& Other & 4 & $7.7 \%$ \\
& Total & 52 & $100.0 \%$ \\
\hline \multirow{5}{*}{ Qualification } & Higher Education & 6 & $11.5 \%$. \\
& BA & 40 & $77.0 \%$. \\
& Diploma & 6 & $11.5 \%$. \\
& Total & 52 & $100.0 \%$ \\
\hline \multirow{5}{*}{ Specialty } & Accountant & 22 & $42.3 \%$ \\
& Business Admin. & 19 & $36.5 \%$ \\
& Economy & 1 & $1.9 \%$ \\
& Finance and banking Sciences & 6 & $11.5 \%$ \\
& Other & 4 & $7.7 \%$ \\
& Total & 52 & $100.0 \%$ \\
\hline \multirow{5}{*}{ Experience } & Less than 5 years & 5 & $9.6 \%$. \\
& From 5 -10 years & 11 & $21.2 \%$ \\
& From 11-15 years & 8 & $15.4 \%$. \\
& Over 15 years. & $53.8 \%$. \\
& Total & $\mathbf{5 2}$ & $\mathbf{1 0 0 . 0 \%}$ \\
\hline
\end{tabular}

The results in (table 1) indicate the following:

For the gender variable, the majority of the sample was male, who formed $75 \%$ of the total number compared to $(25 \%)$ of female. For the job position, managers formed (28\%), director's assistants formed $(30.8 \%)$ and head of section formed $(32.7 \%)$. For the qualification, Bachelor degree holders formed $(77 \%)$ i.e. more than three quarters of the sample, while the percentage of each diploma and postgraduate represented (11.5\%) each. For experience of the staff varied, those who are (over 15 years' experience) more than half of the sample number formed (53.5\%), while those who have (less than 5 years) experience formed (9.6\%). With regard to specialization; the most of sample members are accounting specialization formed (42.3\%), followed by the Business Administration by a (36.5\%), then financial and banking specialist with (11.5\%), and the last are economic specialization (1.9\%).

\subsection{The Statistical Methods Used}

The researchers used the analytical descriptive method to collect and analyze data as the methodology of this research. SPSS software has been used to analyze the research data to get the results through the following statistical quantitative methods:

1) Cronbach' alpha coefficient: to ensure the reliability of the measurement tool (questionnaire).

2) Descriptive statistical method to answer the questions of the research by using:

- Arithmetic means: used to measure the average responses of the sample members to the questionnaire paragraphs.

- Standard Deviation: used to measure the level of dispersion in the answers of respondents on the questionnaire paras. 
- The level of the questionnaire paras were distributed into three levels: average/ high/ low according to the following equation: $5-1=3 / 4=1.3$ range of the period.

Through this the three levels has been divided as follows: from $1.33-2.33=$ high level; from 2.34 to $3.67=$ average level and from 3.68 to $5=$ high level.

3) The method of inferential statistics to test the hypotheses through one sample t-test to answer the study questions. This method is consistent with the research questionnaire which determines each set of phrases for each variable.

\section{Research Results}

\subsection{Answering the Research Questions}

\section{First Question}

Is there a role for the (RCA) system in providing appropriate information for resource allocation in Jordanian commercial banks?

To answer this question, the hypothesis was tested based on questions from (1-8). The calculation pf arithmetic means and standard deviations of the level of (RCA) role were calculated to provide appropriate information to enhance cost management in Jordanian commercial banks as shown in (Table 2):

Table 2. Arithmetic means and standard deviations of the level of (RCA) role in providing appropriate information enhancing the cost management in Jordanian commercial banks

\begin{tabular}{|c|c|c|c|c|c|}
\hline Para No. & Paragraph & $\begin{array}{l}\text { Arithmetic } \\
\text { mean }\end{array}$ & $\begin{array}{l}\text { Standard } \\
\text { deviation }\end{array}$ & $\begin{array}{c}\text { Arranged By level } \\
\text { of importance. }\end{array}$ & Level \\
\hline 1 & $\begin{array}{l}\text { (RCA) provides appropriate information to improve cost } \\
\text { management in the Jordanian commercial banks. }\end{array}$ & 4.00 & .76 & 6 & High \\
\hline 2 & $\begin{array}{l}\text { (RCA) provides financial and non-financial information about the } \\
\text { needs of each resource used. }\end{array}$ & 3.92 & .59 & 7 & High \\
\hline 3 & $\begin{array}{l}\text { (RCA) is characterized by its reliability in the planning of } \\
\text { resources to support the implementation of plans and strategies of } \\
\text { the bank. }\end{array}$ & 3.88 & .70 & 8 & High \\
\hline 4 & $\begin{array}{l}\text { (RCA) provides information which has predictive ability helps in } \\
\text { strategic planning. }\end{array}$ & 4.08 & .76 & 3 & High \\
\hline 5 & $\begin{array}{l}\text { (RCA) is inclusive, by its ability to provide appropriate and } \\
\text { accurate information on the activities of the Bank. }\end{array}$ & 4.10 & .60 & 2 & High \\
\hline 6 & (RCA) is able to detect idle energy in the Bank. & 4.06 & .80 & 4 & High \\
\hline 7 & (RCA) helps to optimize the use of resources in the Bank. & 4.29 & .72 & 1 & high \\
\hline 8 & (RCA) contributes to making appropriate decisions. & 4.02 & .78 & 5 & High \\
\hline 9 & Providing appropriate information to strengthen cost management. & 4.04 & .55 & - & High \\
\hline
\end{tabular}

It is noted in (Table 2) that all the paragraphs of the dimension were high level. Para (7) states that "(RCA) helps to optimize the use of resources in the Bank" came at the first rank at high level, with arithmetic mean (4.29) and standard deviation (0.72). Para (3) which states "(RCA) is characterized by its reliability in the planning of resources to support the implementation of plans and strategies of the bank" ranked the last with high level, arithmetic mean (3.88) and standard deviation (.70).

\section{The Second Questions}

Is there a role for (RCA) system in reducing costs in Jordanian commercial banks?

To answer this question, the hypothesis was tested based on the questions (9-18). The arithmetic means and standard deviations of the level (RCA) role in reducing the costs in the commercial banks as shown in (Table 3): 
Table 3. Arithmetic means and standard deviations of (RCA) system role in reducing the costs in the commercial banks

\begin{tabular}{|c|c|c|c|c|c|}
\hline $\begin{array}{c}\text { Para } \\
\text { No }\end{array}$ & Paragraph & $\begin{array}{c}\text { Arithmetic } \\
\text { mean }\end{array}$ & $\begin{array}{l}\text { Standard } \\
\text { deviation }\end{array}$ & $\begin{array}{c}\text { Arranged By level } \\
\text { of importance }\end{array}$ & Level \\
\hline 9 & $\begin{array}{l}\text { The method used by the bank to determine cost of service cares for short } \\
\text { term which contributes to control of service costs. }\end{array}$ & 3.85 & .67 & 10 & High \\
\hline 10 & $\begin{array}{l}\text { The Bank's approach to determine the cost of service cares for long term } \\
\text { service which contributes to control service costs. }\end{array}$ & 3.92 & .59 & 9 & High \\
\hline 11 & $\begin{array}{l}\text { (RCA) provides appropriate information on how to utilize the available } \\
\text { resources efficiently in the Bank. }\end{array}$ & 4.15 & .64 & 2 & High \\
\hline 12 & (RCA) helps in identifying and measuring costs of resources used. & 4.12 & .70 & 4 & High \\
\hline 13 & (RCA) helps to charge service at a cost amount used of resource. & 3.98 & .70 & 7 & High \\
\hline 14 & (RCA) works on gathering the resources in homogeneous pools & 4.08 & .71 & 6 & High \\
\hline 15 & (RCA) leads to facilitate the cost tracking process and thus its reduction. & 4.17 & .62 & 1 & High \\
\hline 16 & (RCA) leads to identify the behavior of the cost, thus to rationalize it. & 4.11 & .61 & 5 & High \\
\hline 17 & $\begin{array}{l}\text { (RCA) provides a comprehensive view on how to manage energy and } \\
\text { resource costs which resulting to reduction. }\end{array}$ & 4.13 & .60 & 3 & High \\
\hline \multirow[t]{2}{*}{18} & $\begin{array}{l}\text { To know the resources needed precisely for future use helps to reduce } \\
\text { waste. }\end{array}$ & 3.96 & .76. & 8 & High \\
\hline & Costs Reduction & 4.05 & .48. & - & High \\
\hline
\end{tabular}

Table 3 shows that all the paragraphs of the dimension are at a high level. Paragraph (15), which states that "(RCA) leads to facilitate cost tracking process and thus its reduction", ranked first, at a high level, with an arithmetic mean (4.17), and a standard deviation (0.62). Paragraph 9, which states that "The method used by the bank to determine cost of service cares for short term which contributes to control of service costs" has been ranked the last, at a high level, with an arithmetic mean (3.85) and a standard deviation (. 65).

\subsection{Hypotheses Testing}

The First Hypothesis: There is no role for (RCA) System in providing appropriate information for resource allocation in Jordanian commercial banks.

For testing this hypothesis, one sample t-test has been used at hypothetical mean (3.00) of the differences significance in (RCA) in providing appropriate information enhancing the cost management in the commercial banks as shown in (Table 4):

Table 4. First hypothesis testing

\begin{tabular}{ccccccc}
\hline Hypothesis & Arithmetic means & Standard deviation & Test & Degree of freedom & (T) value & significance \\
\hline First & 4.04 & .55 & 3.00 & 51 & 13.648 & .000 \\
\hline
\end{tabular}

Table 4 data shows that $\mathrm{T}$ value calculated reached (13.6480), where arithmetic mean was (4.04), which is greater than hypothetical mean (3.00) and has statistical significance at level $(\alpha \leq 0.05)$, which requires the rejection the Null Hypothesis which states that "There is no role for ((RCA)) System in providing appropriate information for resource allocation in Jordanian commercial banks", and to say that there is a positive role for the (RCA) system in providing appropriate information for resource allocation in Jordanian commercial banks.

The Second Hypothesis: There is no role for (RCA) System in reducing cost in Jordanian commercial Banks.

To test this hypothesis, one sample t-test has been used at hypothetical mean (3.00) of the differences significance in (RCA) system in reducing the costs in the commercial banks as shown in (Table 5):

Table 5. Second hypothesis testing

\begin{tabular}{ccccccc}
\hline Hypothesis & Arithmetic means & Standard deviation & Test & Degree of freedom & (T) value & significance \\
\hline Second & 4.05 & .48 & 3.00 & 51 & 15.759 & .000 \\
\hline
\end{tabular}

Table 5 data shows that $\mathrm{T}$ value calculated reached (15.759), where arithmetic mean was (4.05), which is greater than hypothetical mean (3.00) and has statistical significance at level $(\alpha \leq 0.05)$, which requires the rejection the 
Null Hypothesis which states that "There is no role for (RCA) System in reducing cost in Jordanian commercial Banks", and to say that there is a positive role for the (RCA) system in reducing costs in the commercial banks.

\section{Conclusions}

Through the research the researchers have reached to the following conclusions:

1) (RCA) system is one of the innovation trends. It represents the natural extension between the cost system based on activities and between the German cost accounting systems, and at the same time it complements these two systems and combings their advantages.

2) The most important characteristic of the (RCA) system is its recognition of the existence of idle energy, as it enables the management to shed light on this part and to work on running it efficiently and effectively.

3) (RCA) system has many advantages over other cost systems. It achieves greater accuracy in tracking costs, clarifies the causal relationship between each source and its associated costs, as well as it is accurate in identifying the cost behavior (whether proportional or fixed) and does not charge idle energy on services.

4) The research found that there is a positive role for (RCA) system in cost management in Jordanian commercial banks, as the research sample considers this role exists by the provision of appropriate information and cost reduction.

5) The conclusions of the research show that there is a positive role for the (RCA) system in providing appropriate information to enhance cost management in the Jordanian commercial banks, as the research sample believes that this role is represented in the best use of resources, the provision of appropriate financial and non-financial information on the bank's activities, besides providing predictive capability information which assists in strategic planning, detecting idle energy, and contributes to make proper decisions.

6) The statistical analysis shows that there is a positive role for the (RCA) system in reducing costs in the Jordanian commercial banks, where the research sample believe that this role is represented in several matters. The most important of these matters are: tracking cost, determining cost behavior, measuring costs of the resources used, gathering resources within homogeneous pools, charge the service at the amount of resources cost used, thus lowering the cost and reducing wastage rate.

\section{References}

Abbas, K., \& Wagdi, O. (2014). Cost Systems Adoption In Egyptian Manufacturing Firms: Competitive Study Between $A B C$ and (RCA) Systems. International Economic Conference, SIBIU ROMANIA.

Abkar, S. A. (2014). Modern methods of cost accounting and its role in controlling and reducing costs in industrial, (Field Study on a Sample of Sugar Plants in Sudan). PhD Thesis, Graduate School and Scientific Research, Sudan University of Science and Technology, Sudan.

Abdul-Azim, A. S. (2012). A proposed framework for the integration between the rationalization approach and resource consumption accounting in order to support the competitive position of economic units, applied study. Ain Shams University, Cairo, Egypt.

Abdul-Dayim, S. M. (2014). Proposed introduction for integration of the accounting systems for resource consumption and value path costs with a view to improving the quality of cost measurement. Accounting Research Journal, Tanta University, Egypt.

Abdul, H., \& Yara, S. A. (2012). Accounting for Resource Consumption to Improve the Quality of Cost Accounting System Outputs: An Introduction to Cost Management. Cairo University, Faculty of Commerce, Master of Accounting, unpublished.

Al-Danaf, M. O. (2013). The development of cost systems in the service enterprise using (RCA) to rationalize the resources management" (applied study). Tanta University, Trade Faculty, Master Thesis, Egypt.

Al-Gharouri, A. M. S. (2010). Resource consumption accounting. Egyptian Journal of Business Studies, Egypt.

Al-Hussein, M. K. A. (2016). (RCA) and its role in cost management of medical services (A case study of General Directorate of medical service in the Armed Forces.

Ali, W. A. M. (2013). The Impact of Integration between the Resource Consumption Accounting System and the Project Resource Planning System in Cost Management Support (Field Study), Egypt.

Al-Natur, J. R. (2013). The Effect of Application of (RCA) on Cost Management in Jordanian Industrial Companies. Al-Fikr Accounting Journal, (3). 
Al- Sammani, M. S. (2016). (RCA) and its Role in Cost Management in the Sudanese Banking Sector, field study on the Agricultural Bank of Sudan and Savings Bank and Social Development. Master Thesis, Sudan University of Science and Technology, Sudan.

Al-Swafieri, F. R., \& Nafi', F. B. S. (2013). The development of indirect cost allocation according to the input of time-directed activities and (RCA) applied in Qaseem Cement Company. Jouranl of Trade Faculty for Scientific Researches, 50(2).

Basili, M. (2007). Administrative Accounting; modernity and tradition. Modern library, Egypt.

Elmaci, O. (2014). A model proposal concerning balance scorecard application integrated with resource consumption accounting in enterprise performance management. International Journal of Organizational Leadership, 3, 1-9.

Hijazi, I., \& Su'ad, M. (2012). Modern cost accounting through activities. Dar Osama for publishing and distribution, Amman- Jordan.

Helal, S. (2012). Studies in Advanced Administrative Accounting. Tanta, Tanta University, Faculty of Commerce, Egypt.

Horngren, F. (2012). Cost accounting a managerial Emphasis. Prentice- Hall, Inc. USA.

Khattab, M. S. (2009). A proposed framework for integration between the cost systems based on activity and (RCA) to enhance the management philosophy based on value: Theoretical and field study. Scientific Journal for Trade and Financing, (2).

Kiwan, R. M. (2013). The use of the Accounting Model for (RCA) in the Development of Cost Management Systems in Contemporary Economic Conditions. An Applied Case. Scientific Journal of Economics and Trade, 2(2).

Koumi, A. M. (2007). Proposed Framework for Integrating the Introduction of Resource Consumption Accounting and the Theory of Constraints for Energy Management. Scientific Journal of Economics and Trade, (1).

Ramji, B., Eva, L., \& Sivaramakrishnan, K. (2012). Product Costs as Decision Aids: An Analysis of Alternative Approaches. Accounting Horizons, 26(1), 21-41. https://doi.org/10.2308/acch-10197

Shahin, M. A. (2010). An analytical study of the accounting input for resource consumption as one of the proposed approaches for the development of an activity-based cost measurement method. Scientific Journal of Economy and Trade.

\section{Copyrights}

Copyright for this article is retained by the author(s), with first publication rights granted to the journal.

This is an open-access article distributed under the terms and conditions of the Creative Commons Attribution license (http://creativecommons.org/licenses/by/4.0/). 